\title{
Endodontically treated primary second molar giving rise to formation of dentigerous cyst
}

\author{
Somnath Chakraborty ${ }^{1}$, Pradeep Rastogi² \\ ${ }^{1}$ Assistant Professor, Department of Dentistry, Gouri Devi Institute of Medical Sciences \& Hospital, Durgapur, \\ West Bengal, ${ }^{2}$ Professor and Head, Department of Pediatric and Preventive Dentistry, Seema Dental College \& \\ Hospital, Rishikesh, Uttarakhand, India
}

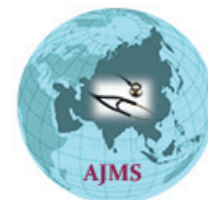

A B S T R A C T

The primary teeth with infected root canals, especially in those cases in which infection has spread to the periradicular tissues are common problem associated with primary dentition. Thus in the field of pediatric dentistry, pulpectomy is considered to be the safe, commonest and successful treatment procedure for primary dentition with periapical inflammation. Sometimes even after pulpectomy, there remains some residual periapical infection which can lead to some complications like dentigerous cyst.Dentigerous cyst is an epithelial-lined developmental cavity that encloses the crown of an unerupted tooth at the cementoenamel junction. The present case report describes a case of a 9 year old boy whose primary second molar was pulpectomized and later on lead to the development of a dentigerous cyst.

\section{Access this article online}

Website:

http://nepjol.info/index.php/AJMS DOI: 10.3126/ajms.v8i2.16246

E-ISSN: 2091-0576

P-ISSN: 2467-9100

Key words: Dentigerous cyst, Inflammatory follicular cyst, Periradicular infection,

Formocresol

\section{INTRODUCTION}

Endodontic therapy plays an important role in destroying bacteria, their by-products and their substrates, by disrupting and destroying the microbial ecosystem through chemical and mechanical methods. The primary teeth with infected root canals, especially in those cases in which infection has spread to the periradicular tissues are common problem associated with primary dentition. Thus in the field of pediatric dentistry, pulpectomy is considered to be the safe, commonest and successful treatment procedure for primary dentition with periapical inflammation. ${ }^{1,2}$

In some rare cases after pulpectomy or pulpotomy, initiation of a dentigerous cyst can be observed in the periradicular region. It occurs due to alteration of the reduced enamel epithelium (after completion of amelogenesis), which results in fluid accumulation between the epithelium and the tooth crown. The continuous and prolonged inflammation may leads to chronic irritation to the dental sac of the unerupted tooth, which in turn leads to the establishment of a dentigerous cyst. ${ }^{3,4}$

A dentigerous cyst is an epithelial-lined developmental cavity that encloses the crown of an unerupted tooth at the cementoenamel junction, thus it is also known as follicular cyst which occur in the periradicular region after pulp treatment. Histological evidence for this cyst suggests that inflammatory exudate induced by an infection spreads to dental follicle, causing separation of reduced enamel epithelium from the enamel leading to development of dentigerous cyst. It can involve any tooth, of which the mandibular third molars and premolars are the most commonly affected, followed by maxillary canine, supernumerary teeth, and, rarely, the central incisor. ${ }^{4,5}$ These cysts are frequently discovered when radiographs are taken to investigate a failure of tooth eruption, a missing tooth, or misalignment.

The following study reports a case of dentigerous cyst associated with pulpectomy treated mandibular primary second molar detected during routine examination in a patient with mixed dentition. 


\section{CASE REPORT}

A male patient aged 9 years reported to the Department of Paedodontics \& Preventive Dentistry, Seema Dental College \& Hospital, Rishikesh who was treated one year ago with lingual arch space maintainer, now came for removal. The patient was advised for an orthopantomogram prior withdrawl of lingual arch space maintainer. Orthopantomograph examination revealed unerupted 35 surrounded by well defined, single unilocular radiolucency around the entire neck of the unerupted premolar (Figure 1). The unilocular radiolucency was of oval shaped and well demarcated by a radiopaque line extending from the mesial root surface of mandibular first premolar up to distal root surface of permanent first molar. On periapical radiograph mandibular lower left primary second molar exhibited the resorption of mesial and distal roots obturated with radiopaque material in the root canal. Hence with all above findings, a dentigerous cyst was suspected.

With the suspected diagnosis of a dentigerous cyst associated with a retained premolar, a decision of marsupialization to be carried out was taken. The treatment choices include extraction of the primary tooth and preservation of the underlying permanent tooth germ so that it can erupt properly into its place. The lower left primary second molar was extracted under local anaesthesia (Figure 2), cystic lining was totally removed and the cystic cavity was thoroughly irrigated, and packed with iodoform gauze (Figures 3 and 4). After successful completion of the surgical treatment the extracted tooth along with soft tissues were send to the Department of Oral Pathology, for histopathological examination (Figure 2). Further histopathological report confirms it of a dentigerous cyst (Figure 5). The patient was recalled after 3 days for change of iodoform dressing, and was kept under follow up until the lower left unerupted second premolar erupts in the oral cavity (Figures 6-10) and finally after six months lower left permanent second premolar erupted in oral cavity (Figures 11 and 12).

\section{DISCUSSION}

Dentigerous cyst are found to be the most commonly occurring odontogenic cysts after radicular cysts. The exact etiology is still unknown, it is believed that due to alteration of the reduced enamel epithelium (after completion of amelogenesis), which results in fluid accumulation between the epithelium and the tooth crown. The continuous and prolonged inflammation may leads to chronic irritation to the dental sac of the unerupted tooth, which in turn leads to the establishment of a dentigerous cyst. The cyst generally occur as a single

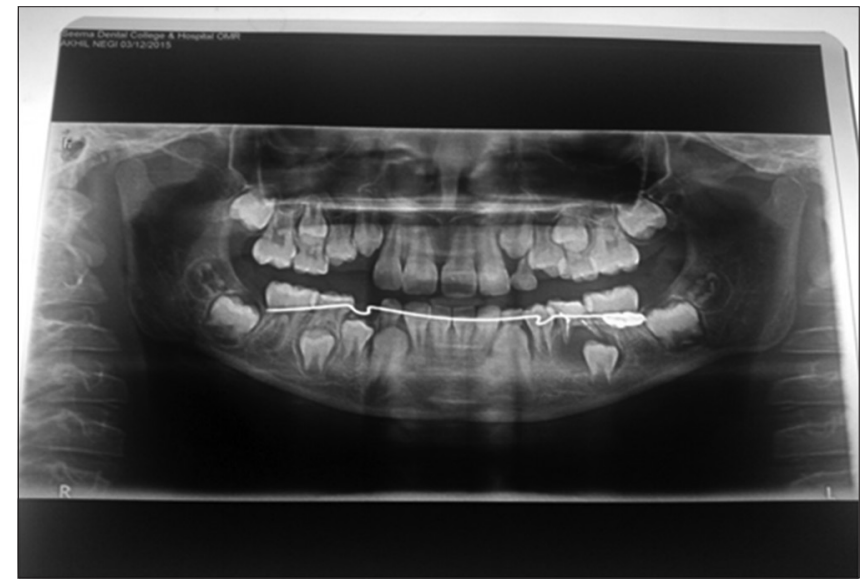

Figure 1: Orthopantomograph examination revealed unerupted 35 surrounded by well defined, single unilocular radiolucency around the entire neck of the unerupted premolar

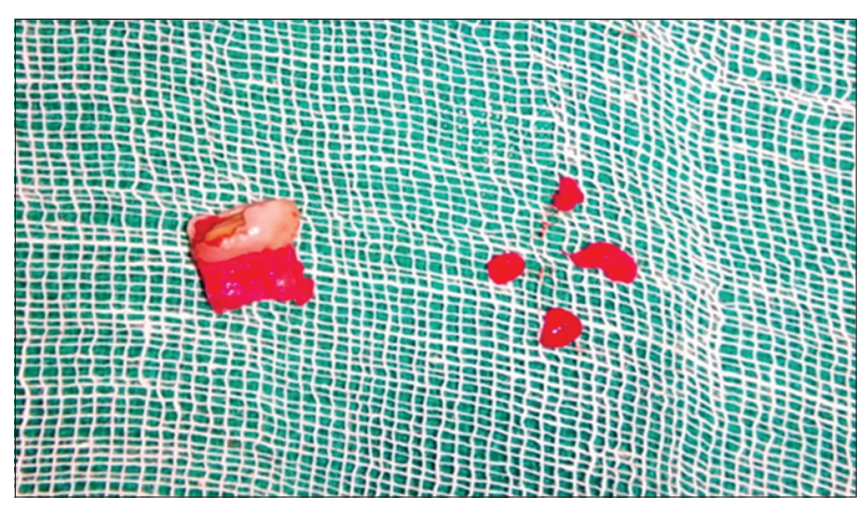

Figure 2: Extraction of primary second molar along with granulation tissue

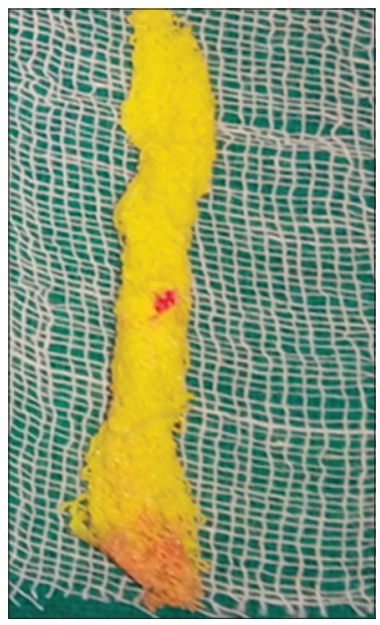

Figure 3: lodoform gauze

lesion, but sometimes bilateral and multiple cysts can occur in association with syndromes like cleidocranial dysplasia, nevus basocelular syndrome, and Hunter's disease. It also occurs in association with alterations of the PTCH gene, superexpression of the P53 gene, and treatments with cyclosporins. ${ }^{5,6}$ 


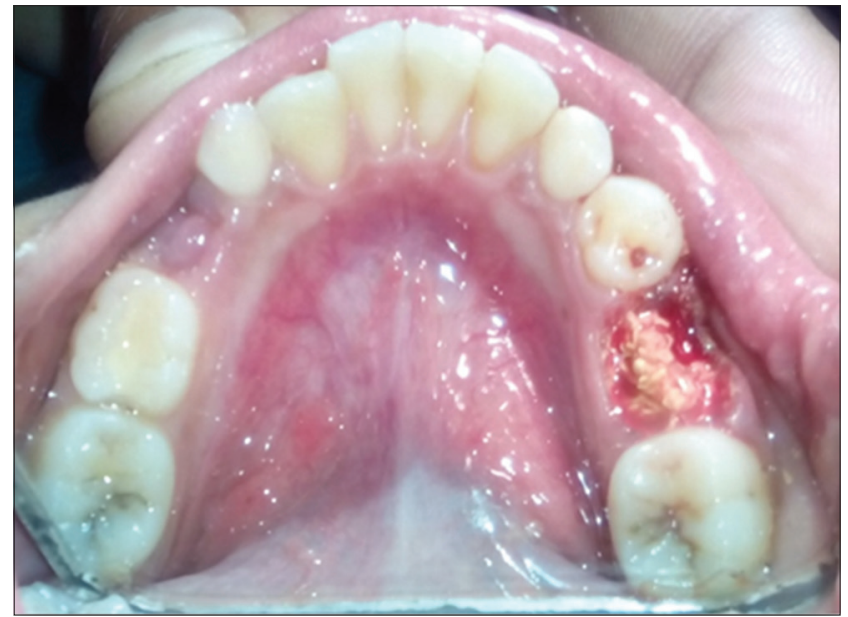

Figure 4: lodoform gauze piece packed into cystic cavity

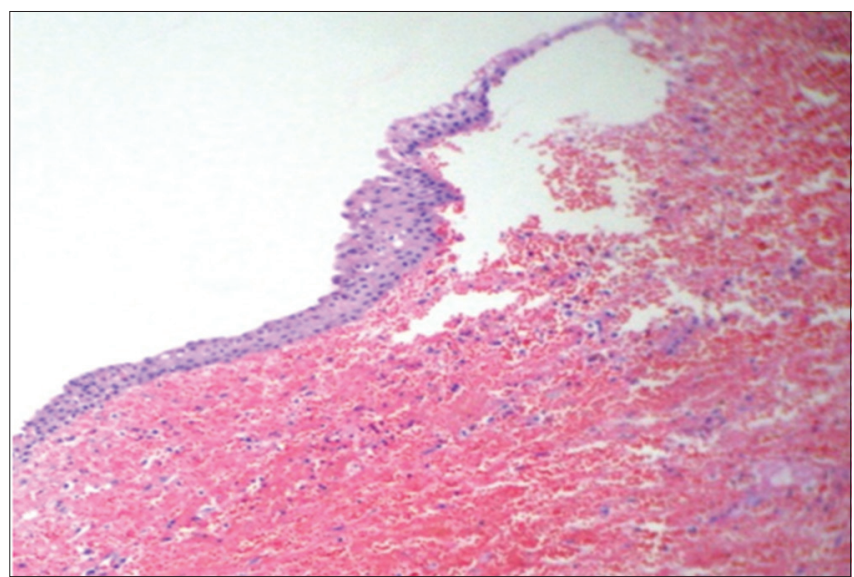

Figure 5: Histopathology report

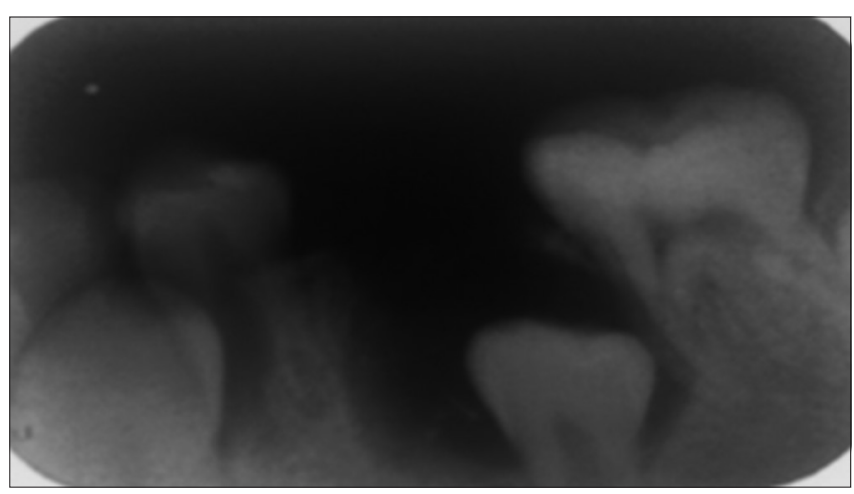

Figure 6: Follow up after 3 days

This type of cyst is generally found in males when compared to females. It is generally found to occur in the transitional dentition between 6-12 years of age group, and is ten times more likely to occur in lower jaw than upper. The occurrence of cyst in association with primary second molars have been assumed that the mandibular molars had a greater susceptibility to caries and get pulpal treatment done, and secondly mandibular second primary molar is more closely associated with its

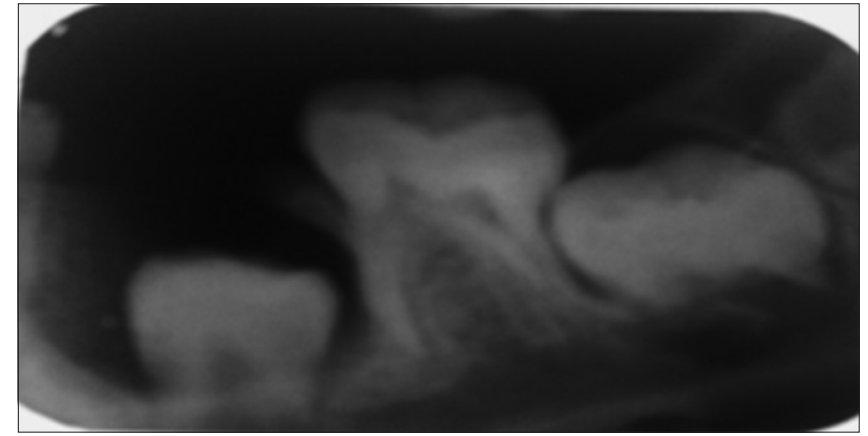

Figure 7: Follow up after 7 days

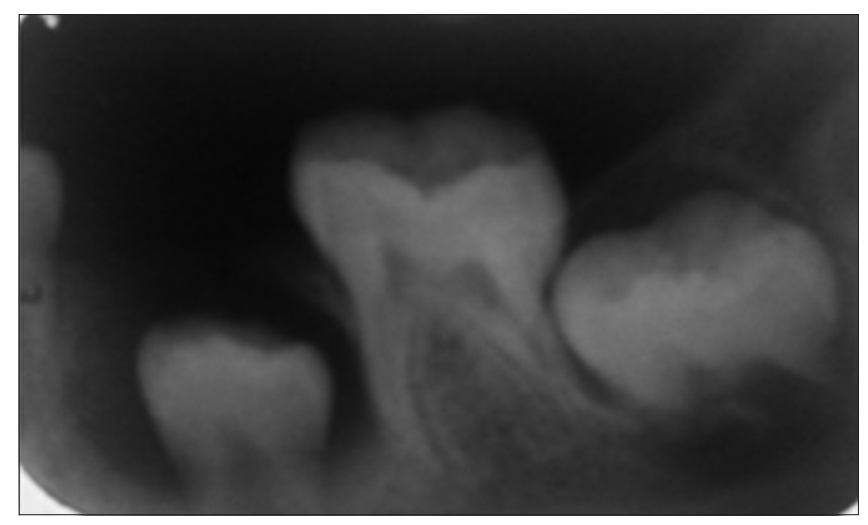

Figure 8: Follow up after 15 days

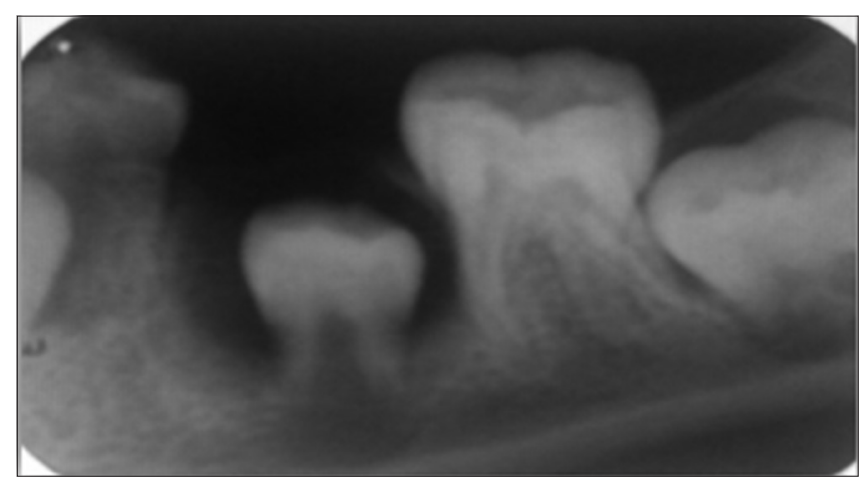

Figure 9: Follow up after 30 days

successor's follicle and such association can more easily facilitate the spread of inflammation in comparison with other primary teeth. ${ }^{6}$

The histopathological report of the present case showed odontogenic lining epithelium of 3-4 layers. The underlying connective tissue is fibrous with evidence of scattered chronic inflammatory cells present in it.

In the present case the treatment choice was made to extract the primary second molar and to preserve the underlying permanent tooth germ so that it can erupt properly into its place. In cases where permanent tooth bud is severely affected, complete enucleation of the cyst along with permanent tooth bud is recommended. In the following 


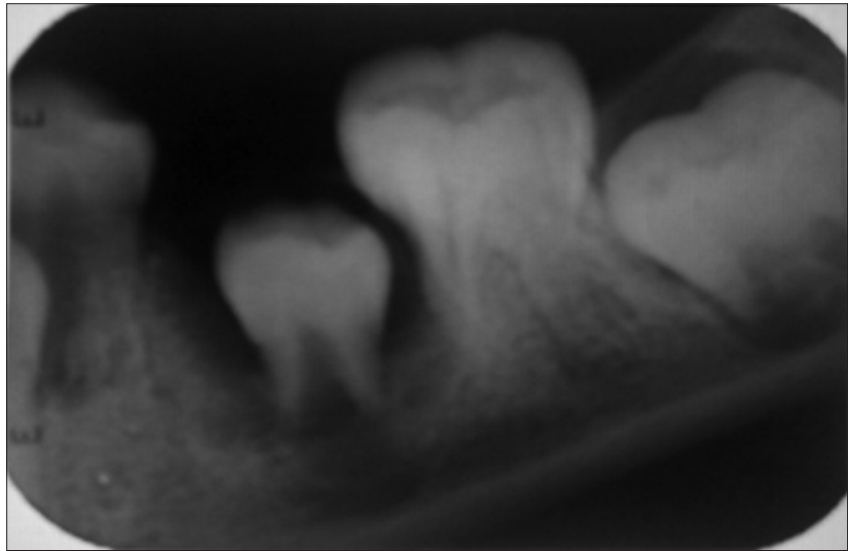

Figure 10: Follow up after 2 months,the premolar is prior to erupt in the oral cavity

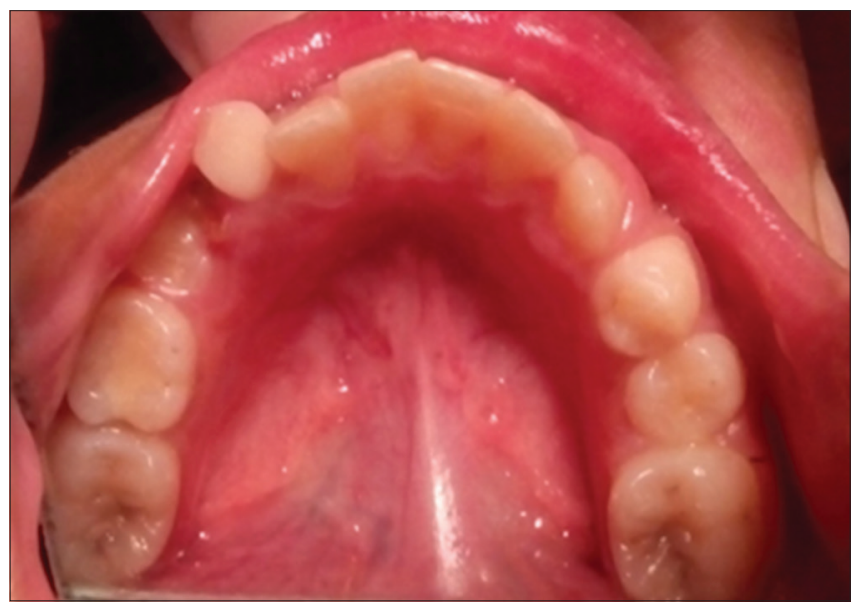

Figure 11: Final Follow up after 6 months,Premolar erupted in the oral cavity

case the retained premolar was found likely to erupt to its own place within a short period of time.

\section{CONCLUSION}

Although pulpectomy is safe, common and successful treatment for decayed primary teeth with periapical
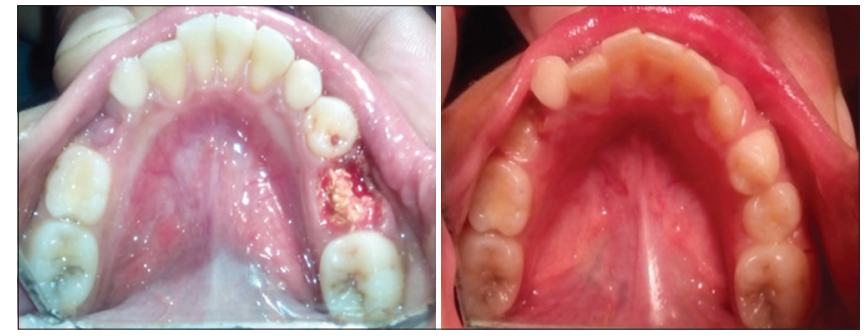

Figure 12: After operative \& Final follow up after Six months

inflammation. Even though after successful treatment, some residual periapical infections might lead to form complications like dentigerous cyst. Hence taking complications to account, dental practitioners must frame up a protocol in their mind that to explain the parents regarding the adverse side effects of endodontic treatment and instruct them to bring their child for periodic checkups.

\section{REFERENCES}

1. Grundy GE, Adkins KF and Savage MW. Cysts associated with deciduous molars following pulp therapy. Aust Dent $\mathrm{J}$ 1984;29:249-256.

2. Alacam A. Long term effects of primary teeth pulpotomies with formocresol, glutaraldehyde-calcium hydroxide, and glutaraldehyde-zinc oxide eugenol on succedaneous teeth. $\mathrm{J}$ Pedod 1989;13:307-313.

3. Aguiló L, Gandía JL. Dentigerous cyst of mandibular second premolar in a five-year-old girl, related to a non-vital primary molar removed one year earlier: A case report. J Clin Pediatr Dent 1998;22(2):155-158.

4. Lustig JP, Schwartz-Arad D and Shapira A. Odontogenic cysts related to pulpotomized deciduous molars. Clinical features and treatment outcome. Oral Surg Oral Med Oral Pathol Oral RadiolEndod 1999;87:499-503.

5. Da Silva TA, De Sá AC, Zardo M, Consolaro A and Lara VS. Inflammatory follicular cyst associated with an endodontically treated primary molar: A case report. ASDC J Dent Child 2002; 69(3):271-274.

6. Asián-González E, Pereira-Maestre $\mathrm{M}$, Conde-Fernández D, Vilchez I, Segura-Egea JJ and Gutiérrez-Pérez JL. Dentigerous cyst associated with a formocresol pulpotomized deciduous molar. J Endod 2007;33(4):488-492.

\footnotetext{
Authors Contribution:

SC - Concept and Designing the rare case report, reviewed the literature, entire manuscript preparation and critical revision of the manuscript. PR - Concept and Review of Case Report.

Source of Support: Nil, Conflict of Interest: None declared.
} 